\title{
Body Surface Area
}

National Cancer Institute

\section{Source}

National Cancer Institute. Body Surface Area. NCI Thesaurus. Code C25157.

A measure of the 2-dimensional extent of the body surface (i.e., the skin). Body surface area (BSA) can be calculated by mathematical formula or from a chart that relates height to weight. BSA is often an important factor in dosing. 